\title{
Is There a Rationale for Structural Quality Assurance in Esophageal Surgery?
}

\author{
Torben Glatz Jens Höppner \\ Department of General and Visceral Surgery, University of Freiburg, Freiburg i.Br., Germany
}

\section{Keywords}

Esophageal cancer - Esophagectomy - Structural quality . Hospital volume

\section{Summary}

Background: Advances regarding perioperative mortality rates and oncological outcomes after esophagectomy have been reported extensively by specialized high-volume centers in Europe and the USA over the last decade. However, recent database analyses reveal that the perioperative mortality of esophagectomy remains high in these countries, indicating a discrepancy between surgical quality in baseline hospitals and specialized centers. Methods: This article provides an overview over the existing literature on the correlation between structural quality, procedural volume, and surgical outcome in esophageal surgery. Results: Structural, procedural and outcome measures can be used to assess the quality of surgical treatment and perioperative management. Surgical procedures on the esophagus for both benign and malignant diseases are rare and typically associated with high perioperative morbidity and mortality. Usually, direct outcome measures do not provide enough statistical power to actually identify differences in surgical quality between hospitals, making structural quality measures the only feasible parameter to compare the quality of esophageal surgery among different centers. Several analyses from different countries have shown a strong correlation between hospital volume and postoperative mortality. Data from countries in which esophageal surgery has been centralized indicate beneficial effects of a centralized health care system on postoperative mortality after esophagectomy. Additionally, only high-volume centers generally provide optimal preoperative and postoperative management and comprehensive access to modern multimodal treatment. In Germany, esophageal surgery is still decentralized, but hospitals performing complex esophageal procedures have to fulfill minimum caseload requirements of 10 cases per year. In practice, these requirements are not met by the majority of hospitals and a detrimental effect on the achieved surgical outcomes can be noted. Conclusion: Therefore, we conclude that structural quality assurance is crucial to further reduce postoperative morbidity after esophageal surgery and to improve long-term results.

(c) 2017 S. Karger GmbH, Freiburg

\section{Recent Advances in Esophageal Surgery}

A huge variety of studies from Asia, Europe, and the USA has been published during the last decade, demonstrating a significant improvement in esophageal surgery regarding postoperative outcome, e.g. postoperative mortality rate, as well as oncological longterm results after esophagectomy for esophageal cancer $[1,2]$. Improvements in surgical technique, e.g. the introduction of minimally invasive techniques in esophageal surgery, perioperative management, anesthesia, intensive care medicine, and interdisciplinary management of postoperative complications, have contributed to a reduced postoperative morbidity and mortality $[3,4]$. Large case series from high-volume centers frequently report a postoperative mortality rate of under $2 \%$ and a median hospitalization time as low as 8 days for these complex procedures [5-7].

The widespread implementation of multimodal protocols in the treatment of esophageal cancer, e.g. the use of neoadjuvant chemoradiation and perioperative chemotherapy, has improved longterm results, with several randomized controlled trials and retrospective analyses reporting 5 -year survival rates of nearly $50 \%$ for selected locally advanced tumors treated within these multimodal protocols [8-13].

Esophageal surgery beyond the specialized high-volume centers is still characterized by a heavy postoperative morbidity and mortality, and outcomes vary widely between different countries and

\section{KARGER}

() 2017 S. Karger GmbH, Freiburg

Fax +497614520714 
hospitals [14]. Database analyses from the USA show an overall inhospital mortality of $8 \%$ over the last two decades, while the German register data reveal even higher figures of approximately $10 \%$ for postoperative mortality in the time period 2006-2013 [15-17].

These figures give the impression that the quality of care in esophageal surgery is not yet as good as expected. A similar situation exists for other complex abdominal surgeries, e.g. pancreatic resections [18].

While several studies have shown that reduction of postoperative mortality and improvement of long-term results are possible in esophageal surgery when performed in specialized high-volume centers, the advances have to be implemented in clinical practice to achieve better results for the majority of patients.

\section{Measuring Surgical Quality in Esophageal Surgery}

In times of benchmarking hospital results and ensuring a comparability of different medical centers and physicians as well as surgeons, indicators for hospital quality have to be chosen carefully to be comprehensive, outcome-related, and tamper-resistant [19].

In general, a variety of measures is available to reflect surgical quality: structural measures, process measures, and direct outcome measures [20]. Case volume, radicality of resection, and postoperative morbidity and mortality have been identified as key performance indicators in esophageal surgery [21].

Choosing the right measure depends most importantly on two relevant attributes of the procedure: i) the baseline risk and ii) how commonly the procedure is performed at individual hospitals. Esophagectomy typically has a low annual caseload and a high baseline risk. Therefore, direct outcome measures usually do not provide enough statistical power to actually identify differences in surgical quality between hospitals. Structural measures, especially procedural volume, are likely the only practical quality indicator [20].

Structural measures include an extensive list of variables reflecting the setting in which surgical care is delivered, including the hospitals' resources and measures related directly or indirectly to staff expertise, coordination, and organization [20].

Structural measures addressed in the literature on esophageal surgery are hospital volume, specialization, organization, and centralization, with different levels of evidence supporting the feasibility of these variables as suitable parameters [22].

Among structural variables, procedural volume is most commonly used as a surrogate for surgical quality. Procedural volume can be either measured at the surgeon or hospital level. The correlation between procedural volume and surgical outcome is extensively reviewed in the literature.

\section{Association between Hospital Volume and Surgical Outcome in Esophageal Surgery}

A correlation between hospital volume and postoperative mortality has been established for major abdominal cancer surgery, while the effect of procedural volume on long-term outcome remains uncertain $[23,24]$.

As early as 2004, a systematic literature review revealed a strong correlation between postoperative mortality and hospital volume for esophageal cancer surgery [25]. The authors suggested a cut-off of at least 20 procedures per year to reduce postoperative mortality after esophagectomy.

Two different reviews from 2010 and 2012 confirmed these results and showed less complications and shorter hospitalization times in high-volume centers compared to low-volume hospitals. It was noted that the definition of 'high volume' varied significantly between the different studies $[22,26]$. This effect was reproduced in several more recent studies in Europe and the USA [14-17, 27-31].

A recent analysis of the Nationwide Inpatient Sample in the USA from 1998 to 2011 demonstrated a strong correlation between hospital volume and postoperative mortality after esophagectomy $[15,16]$, as did a large European multicenter trial including 2,944 patients between 2000 and 2010 [28]. A Swedish study suggests annual and cumulative surgeon volume rather than hospital volume as a predictor of perioperative mortality [26].

The etiology and causality of the correlation between volume and outcome are still not completely understood. The simple focus on volume can only be a starting point for further studies to determine more specific factors associated with surgical quality [32].

\section{Evidence for a Benefit of Centralization}

Centralization of complex cancer surgery has become a trend, and treatment of cancer patients in specialized centers has become more common over the last decades [33, 34].

Beneficial effects on postoperative mortality rates were observed after centralization of esophageal surgery in the Netherlands at the beginning of this century [35]. A population-based study from the Netherlands showed that hospital volume accounted for only $50 \%$ of the variation in mortality between the hospitals. Differences in infrastructure, patient selection, surgical expertise, and availability of multidisciplinary teams seem to be equally important [36].

International comparisons between countries with a centralized and a non-centralized health care system show a reduction of postoperative mortality in countries in which centralization of esophageal surgery is mandatory, e.g. when comparing England and the United States: An analysis of the Nationwide Inpatient Sample since 2001 demonstrates a reduced in-hospital mortality in England ( 4.2 vs. $5.5 \%$ in the USA). This effect goes along with a significant difference in median case load per center (17.5 in England vs. 2 in the USA) [29].

The process of centralization does not only require the accredited centers to perform a certain number of operations per year but also needs to guarantee access to facilities not present in the typical general surgery unit, such as 24-h availability of an experienced endoscopy unit, an interventional radiology, a specialized intensive care unit, and trained thoracic and cardiovascular surgeons [37]. 
Fig. 1. Percentage of cases treated in institutions in Germany that did not meet minimum caseload requirements from 2005 to 2011. Esophageal surgery has the highest percentage of patients treated outside of hospitals that fulfill minimum caseload requirements of all applicable procedures. ${ }^{* 1}$ Institutions that only performed post-mortem organ removal have been excluded; ${ }^{\star 2}$ two-tailed $\mathrm{p}$-value for linear trend (2006-2011), <0.05. Adapted from [39]. Reprinted with kind permission. ${ }^{\circ} 2017$ Deutscher Ärzteverlag GmbH. All rights reserved.

\section{Percent}

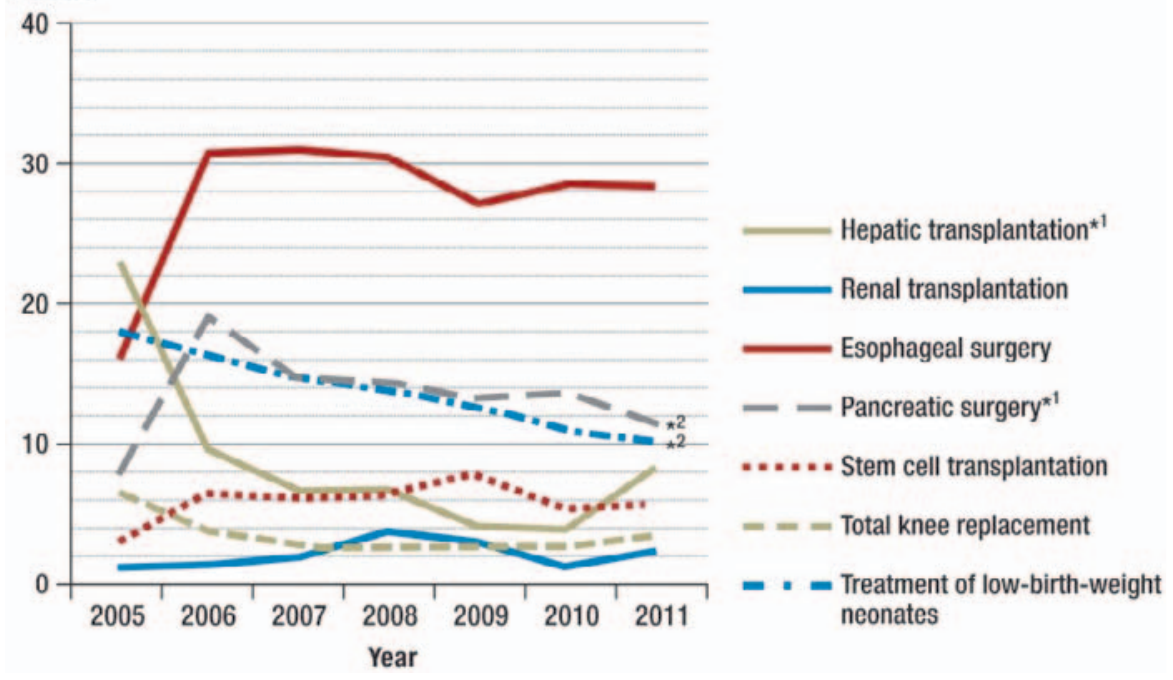

These facilities are crucial in esophageal surgery to properly treat intraoperative and postoperative complications and therefore directly affect surgical outcome [38].

Additionally, accredited centers have to guarantee the presence of interdisciplinary teams consisting of surgeons, medical oncologists, and radiotherapists specialized in the multimodal therapy of esophageal cancer, providing an optimal treatment concept and improving the patients' long-term survival.

\section{Esophageal Surgery in Germany: Minimum Caseload Requirements}

Due to the evidence connecting hospital volume and surgical outcome for complex surgical procedures, the German Federal Joint Committee has established minimum caseload requirements for procedures like complex esophageal surgery, complex pancreatic surgery, and liver transplantation.

In Germany, until today, the majority of hospitals which treat patients requiring complex esophageal surgery do not meet the required caseload of 10 cases per year (fig. 1). In 2011, there was a registered number of 411 centers, of which only 130 institutions fulfilled the minimum caseload requirement. These centers treated 2,634 patients with a median caseload of 20 , while the remaining 281 hospitals treated 1,039 patients with a median caseload of 4 . Compared to all other procedures that require a minimum caseload, esophageal surgery has the highest rate of institutions which do not fulfill the requirements as well as the highest rate of patients treated outside of hospitals that meet the requirements. These numbers have been stable over the last years without significant improvement. The introduction of minimum caseload requirements had little or no effect on the centralization process of esophageal surgery [39].

A retrospective analysis of German hospital discharge data between 2006 and 2013 showed a significantly reduced risk for peri- operative mortality in hospitals that meet the minimum caseload requirements compared to those that do not (9 vs. $12.7 \%$ ), with an adjusted odds ratio of 0,7 [18].

Additionally, the chosen cut-off of 10 procedures per year does not seem justified when reviewing the literature. Several studies analyzing the correlation between postoperative mortality and hospital volume show a significant decrease in mortality in centers with 20 or more procedures a year [16,36]. A recent study from France even demonstrates a further reduction in postoperative mortality in centers with more than 40 or more than 60 procedures per year even for low-risk patients [31], and results from a large European multicenter trial demonstrate a significant reduction of postoperative mortality for a procedural volume of more than 80 operations per year [28]. A study from the Netherlands in more than 10,000 patients suggests that postoperative mortality reaches a plateau after 40-60 esophagectomies per year [30], indicating a reasonable cut-off far from the minimum caseload required in Germany.

\section{Conclusion}

In summary, a huge discrepancy can be noted between the surgical outcomes of esophagectomy published by specialized highvolume centers and the actual outcomes extracted from data registers.

Several studies analyzing the correlation between procedural volume and surgical outcome for complex esophageal surgery suggest a strong inverse correlation between the annual number of procedures performed and postoperative mortality, as well as regarding hospitalization time and other outcome parameters. The process of formation of specialized centers for esophageal surgery in other European countries has proven to reduce postoperative mortality.

In Germany, hospitals performing esophageal surgery are required to fulfill a minimum caseload of 10 cases per year. While 
recent studies suggest a significant improvement of surgical outcome measures with a caseload of 40-60 cases per year, this number seems to be chosen arbitrarily. Additionally, this requirement is not met by the majority of centers performing esophageal surgery in Germany.

We conclude that structural quality assurance, such as reasonable caseload requirements, the formation of specialized centers, and the strict enforcement of these guidelines, will be necessary to further decrease postoperative mortality after esophagectomy. Fu- ture studies will have to prove whether improvements in long-term survival and regarding the patients' quality of life can be likewise achieved.

\section{Disclosure Statement}

The authors have no conflict of interest to disclose.

\section{References}

1 Makowiec F, Baier P, Kulemann B, Marjanovic G, Bronsert P, Zirlik K, Henke M, Hopt UT, Hoeppner J: Improved long-term survival after esophagectomy for esophageal cancer: influence of epidemiologic shift and neoadjuvant therapy. J Gastrointest Surg 2013;17: 1193-1201.

2 Markar SR, Karthikesalingam A, Low DE: Enhanced recovery pathways lead to an improvement in postoperative outcomes following esophagectomy: systematic review and pooled analysis. Dis Esophagus 2015;28: $468-475$.

3 Molena D, Mungo B, Stem M, Lidor AO: Incidence and risk factors for respiratory complications in patients undergoing esophagectomy for malignancy: a NSQIP analysis. Semin Thorac Cardiovasc Surg 2014; 26:287-294.

4 Paul S, Altorki N: Outcomes in the management of esophageal cancer. J Surg Oncol 2014;110:599-610.

5 Luketich JD, Pennathur A, Awais O, Levy RM, Keeley S, Shende M, Christie NA, Weksler B, Landreneau RJ, Abbas G, Schuchert MJ, Nason KS: Outcomes after minimally invasive esophagectomy: review of over 1000 patients. Ann Surg 2012;256:95-103.

6 Phillips AW, Dent B, Navidi M, Immanuel A, Griffin SM: Trainee involvement in Ivor Lewis esophagectomy does not negatively impact outcomes. Ann Surg 2016;DOI: 10.1097/SLA.0000000000002047.

7 Glatz T, Marjanovic G, Kulemann B, Sick O, Hopt UT, Hoeppner J: Hybrid minimally invasive esophagectomy vs. open esophagectomy: a matched case analysis in 120 patients. Langenbecks Arch Surg 2017;DOI: 10.1007/s00423-017-1550-4.

8 Cunningham D, Allum WH, Stenning SP, Thompson JN, van de Velde CJH, Nicolson M, Scarffe JH, Lofts FJ, Falk SJ, Iveson TJ, Smith DB, Langley RE, Verma M, Weeden S, Chua YJ; MAGIC Trial Participants: Perioperative chemotherapy versus surgery alone for resectable gastroesophageal cancer. N Engl J Med 2006; 355:11-20.

9 Ychou M, Boige V, Pignon J-P, Conroy T, Bouche O, Lebreton G, Ducourtieux M, Bedenne L, Fabre J-M, Saint-Aubert B, Geneve J, Lasser P, Rougier P: Perioperative chemotherapy compared with surgery alone for resectable gastroesophageal adenocarcinoma: an FNCLCC and FFCD multicenter phase III trial. J Clin Oncol 2011;29:1715-1721

10 van Hagen P, Hulshof MC, van Lanschot JJ, et al.; CROSS Group: Preoperative chemoradiotherapy for esophageal or junctional cancer. N Engl J Med 2012; 366:2074-2084.

11 Shapiro J, van Lanschot JJ, Hulshof MC, et al; CROSS study group: Neoadjuvant chemoradiotherapy plus surgery versus surgery alone for oesophageal or junctional cancer (CROSS): long-term results of a randomised controlled trial. Lancet Oncol 2015;16:10901098.
12 Hoeppner J, Zirlik K, Brunner T, Bronsert P, Kulemann B, Sick O, Marjanovic G, Hopt UT, Makowiec F: Multimodal treatment of locally advanced esophageal adenocarcinoma: which regimen should we choose? Outcome analysis of perioperative chemotherapy versus neoadjuvant chemoradiation in 105 patients. J Surg Oncol 2014;109:287-293.

13 Glatz T, Bronsert P, Schafer M, Kulemann B, Marjanovic G, Sick O, Hopt UT, Zirlik K, Makowiec F, Hoeppner J: Perioperative platin-based chemotherapy for locally advanced esophagogastric adenocarcinoma: postoperative chemotherapy has a substantial impact on outcome. Eur J Surg Oncol 2015;41:1300-1307.

14 Dikken JL, van Sandick JW, Allum WH, Johansson J, Jensen LS, Putter H, Coupland VH, Wouters MW, Lemmens VE, van de Velde CJ, van der Geest LG, Larsson H, Cats A, Verheij M: Differences in outcomes of oesophageal and gastric cancer surgery across Europe. Br J Surg 2013;100:83-94.

15 Fuchs HF, Harnsberger CR, Broderick RC, Chang DC, Sandler BJ, Jacobsen GR, Bouvet M, Horgan S: Mortality after esophagectomy is heavily impacted by center volume: retrospective analysis of the Nationwide Inpatient Sample. Surg Endosc 2016;DOI: 10.1007/s00464016-5251-9.

16 Fuchs HF, Harnsberger CR, Broderick RC, Chang DC, Sandler BJ, Jacobsen GR, Bouvet M, Horgan S: Simple preoperative risk scale accurately predicts perioperative mortality following esophagectomy for malignancy. Dis Esophagus 2017;DOI: 10.1111/dote.12451.

17 Nimptsch U, Peschke D, Mansky T: Minimum case load requirements and in-hospital mortality: observational study using nationwide hospital discharge data from 2006 to 2013 (Article in German). Gesundheitswesen 2016;DOI: 10.1055/s-0042-100731.

18 Nimptsch U, Krautz C, Weber GF, Mansky T, Grutzmann R: Nationwide In-hospital Mortality Following Pancreatic Surgery in Germany is Higher than Anticipated. Ann Surg 2016;264:1082-1090.

19 Mansky T, Nimptsch U: Hospital quality measurement - what matters? (Article in German). Z Evid Fortbild Qual Gesundhwes 2014;108:487-494.

20 Birkmeyer JD, Dimick JB, Birkmeyer NJ: Measuring the quality of surgical care: structure, process, or outcomes? J Am Coll Surg 2004;198:626-632.

21 Gockel I, Ahlbrand CJ, Arras M, Schreiber EM, Lang $\mathrm{H}$ : Quality management and key performance indicators in oncologic esophageal surgery. Dig Dis Sci 2015; 60:3536-3544.

22 Courrech Staal EF, Wouters MW, Boot H, Tollenaar RA, van Sandick JW: Quality-of-care indicators for oesophageal cancer surgery: a review. Eur J Surg Oncol 2010;36:1035-1043.
23 Gruen RL, Pitt V, Green S, Parkhill A, Campbell D, Jolley D: The effect of provider case volume on cancer mortality: systematic review and meta-analysis. CA Cancer J Clin 2009;59:192-211.

24 Reames BN, Ghaferi AA, Birkmeyer JD, Dimick JB Hospital volume and operative mortality in the modern era. Ann Surg 2014;260:244-251.

25 Metzger R, Bollschweiler E, Vallböhmer D, Maish M, DeMeester TR, Hölscher AH: High volume centers for esophagectomy: what is the number needed to achieve low postoperative mortality? Dis Esophagus 2004;17: 310-314.

26 Markar SR, Karthikesalingam A, Thrumurthy S, Low DE: Volume-outcome relationship in surgery for esophageal malignancy: systematic review and metaanalysis 2000-2011. J Gastrointest Surg 2012;16:10551063

27 Fumagalli U, Bersani M, Russo A, Melis A, de Pascale S, Rosati R: Volume and outcomes after esophageal cancer surgery: the experience of the Region of LombardyItaly. Updates Surg 2013;65:271-275.

28 Markar S, Gronnier C, Duhamel A, Bigourdan J-M Badic B, Du Rieu MC, Lefevre JH, Turner K, Luc G, Mariette C: Pattern of Postoperative Mortality After Esophageal Cancer Resection According to Center Volume: Results from a Large European Multicenter Study. Ann Surg Oncol 2015;22:2615-2623.

29 Munasinghe A, Markar SR, Mamidanna R, Darzi AW, Faiz OD, Hanna GB, Low DE: Is it time to centralize high-risk cancer care in the United States? Comparison of outcomes of esophagectomy between England and the United States. Ann Surg 2015;262:79-85.

30 Henneman D, Dikken JL, Putter H, Lemmens VE, van der Geest LG, van Hillegersberg R, Verheij M, van de Velde CJ, Wouters MW: Centralization of esophagectomy: how far should we go? Ann Surg Oncol 2014;21: 4068-4074.

31 Pasquer A, Renaud F, Hec F, Gandon A, Vanderbeken M, Drubay V, Caranhac G, Piessen G, Mariette C: Is centralization needed for esophageal and gastric cancer patients with low operative risk?: a nationwide study. Ann Surg 2016;264:823-830.

32 Greenberg CC, Zinner MJ: Surgical volume. An American perspective (Article in German). Chirurg 2007;78: 1028-1036.

33 Stitzenberg KB, Meropol NJ: Trends in centralization of cancer surgery. Ann Surg Oncol 2010;17:28242831.

34 Stitzenberg KB, Sigurdson ER, Egleston BL, Starkey RB, Meropol NJ: Centralization of cancer surgery: implications for patient access to optimal care. J Clin Oncol 2009;27:4671-4678. 
35 Wouters MW, Karim-Kos HE, Le Cessie S, Wijnhoven BP, Stassen LP, Steup WH, Tilanus HW, Tollenaar RA: Centralization of esophageal cancer surgery: does it improve clinical outcome? Ann Surg Oncol 2009;16: 1789-1798.

36 Wouters MW, Krijnen P, Le Cessie S, Gooiker GA Guicherit OR, Marinelli AW, Kievit J, Tollenaar RA: Volume- or outcome-based referral to improve quality of care for esophageal cancer surgery in The Netherlands. J Surg Oncol 2009;99:481-487.
37 Parise P, Elmore U, Fumagalli U, De Manzoni G, Giacopuzzi S, Rosati R: Esophageal surgery in Italy. Criteria to identify the hospital units and the tertiary referral centers entitled to perform it. Updates Surg 2016; 68:129-133.

38 Tol JA, van Gulik TM, Busch OR, Gouma DJ: Centralization of highly complex low-volume procedures in upper gastrointestinal surgery. A summary of systematic reviews and meta-analyses. Dig Surg 2012;29:374383.
39 Peschke D, Nimptsch U, Mansky T: Achieving minimum caseload requirements - an analysis of hospital discharge data from 2005-2011. Dtsch Arztebl Int 2014;111:556-563. 